\title{
LibOUAL Results Bring More Questions than Answers
}

\author{
Kimberly K. Vardeman and Jingjing Wu \\ Texas Tech University Libraries, USA
}

\begin{abstract}
The Texas Tech University Libraries conducted the LibQUAL survey in 2017. After receiving the survey results, the libraries had many unanswered questions-what is the next step? What are the problem areas? Which problems should be addressed first?

The website was identified as a topic that merited further study. The user experience (UX) department collaborated with the web librarian to outline projects to gather more evidence that would guide their action. They used a variety of research methods to assess the website: $\mathrm{X} / \mathrm{O}$ tests to allocate valuable home page real estate to the services and features of most interest to users; card sorting to design a more understandable website navigation; usability testing to evaluate whether common tasks could be performed easily; heuristic evaluations of frequently used webpages to see if they conformed to accepted usability principles; A/B tests to compare different design prototypes; and subsequent surveys to re-evaluate the modifications. By the triangulation of several data sources, they made informed decisions about how to improve the website.
\end{abstract}

As an initial step, LibQUAL does not offer specific answers, but suggests potential directions for further study. This paper describes ways to iteratively test the UX of a website using several complementary methods following an exploratory survey. These strategies extend the value of survey results, making assessments more effective and practical. This pattern can be used not only for a website but for evaluating other services.

\section{Introduction}

In 2011, the Texas Tech University (TTU) Libraries conducted the LibQUAL survey. After receiving the results, the library dean made the comment, "LibQUAL results bring more questions than answers." At that time, the results were not well disseminated beyond administration, and limited action was taken in response to the survey. In 2017, under a different dean and with a newly-formed user experience (UX) department, the TTU Libraries opted to conduct LibQUAL again. They used a census and received 3,631 valid surveys-a sizable increase over the 584 received in 2011 when they used a sampling method. Participants came from all the sub-groups defined by LibQUAL, and their subject areas covered all the disciplines the university offered. In addition, 1,433 participants shared comments and suggestions about the libraries' services and resources. The libraries wanted the LibQUAL findings to have a greater impact on services, resources, and spaces than they had in 2011-how to interpret the results, how to share them, and how to make improvements became a challenge for the libraries and the UX department.

\section{Comment Coding and Data Revisualization}

Reviewing best practices for interpreting LibQUAL results was a useful starting point, such as the report, "Libraries Act on Their LibQUAL+ Findings: From Data to Action." 1 There were a few presentations that focused on the practical aspects of analysis: "Analysis and Interpretation of the LibQUAL Results," 2 and "It's Not about You! Using LibQUAL at Brown University and at the University of Connecticut Libraries." ${ }^{3}$ The latter was informative about the importance of coding comment data. Both presentations gave useful guidance on interpreting charts and understanding zones of tolerance. They provided instructions for identifying what was actionable from the results by cross-tabulating desired and adequacy mean scores in order to determine what users rated as most needed but least adequate.

Organizing the open-ended comments was a key part of the analysis process. The LibQUAL email list was tremendously helpful at this stage as other librarians discussed their strategies for reviewing comments, such as using Brown University's 2005 Codebook $^{4}$ as a guide, using an emergent coding strategy, ${ }^{5}$ and developing a "comments slicer" in Excel. ${ }^{6}$ The initial work was completed by the UX department's library associate (a 
staff position) who carefully coded over 1,400 open-ended responses into topics and sub-topics. The UX librarian served as the second coder, and together they refined codebook definitions and ensured adequate inter-coder reliability.

The survey results notebook generated by ARL included graphics that were not easily understoodcomplicated, multicolor radar charts, and high-low charts with interior and exterior bars. Those graphics communicated a great deal of information, but they were not effective at showing "at a glance" what results were most significant and actionable. The UX department and UX team members-a group of a dozen employees from other departments-collaborated to create new charts and infographics to highlight key findings. The revisualization and reorganization of the data made relevant information more understandable to stakeholders. Because UX team members represented different departments, they developed strategies for sharing data. They varied their approach, either scheduling additional meetings for a presentation and discussion, having team members report the data to their own areas during already-scheduled department meetings, or by sharing selected summary data via email.

\section{LibQUAL Results about the Website}

The UX team cross-tabulated desired and adequacy scores to determine what users rated as most needed but least adequate and identified the website as a problematic area. In the 2017 survey, two questions were directly related to the website. One was the core question in the Information Control section: "A library Web site enabling me to locate information on my own." Another was a local question: "Ability to navigate library Web pages easily." The general (overall) results of these two questions showed that the perceived mean was between the desired and the minimum, which means that the website was neither terrible nor excellent. However, when looking closely at the results by user group, respondents from different user groups scored the website differently. This study focused on results from undergraduate students, graduate students, and faculty members. Figure 1, Perceived Mean versus Minimum-Desired Range, shows the differences between user groups:

- Undergraduate students had the lowest expectations on locating information or navigating the website, and they were comparatively satisfied with the current website.

- Graduate students perceived the website to be only slightly higher than their minimum-acceptable level.

- Faculty members had the highest expectations, but their perceived control over locating information and navigating the website was below acceptable levels. 
Figure 1: Perceived Mean versus Minimum-Desired Range

9

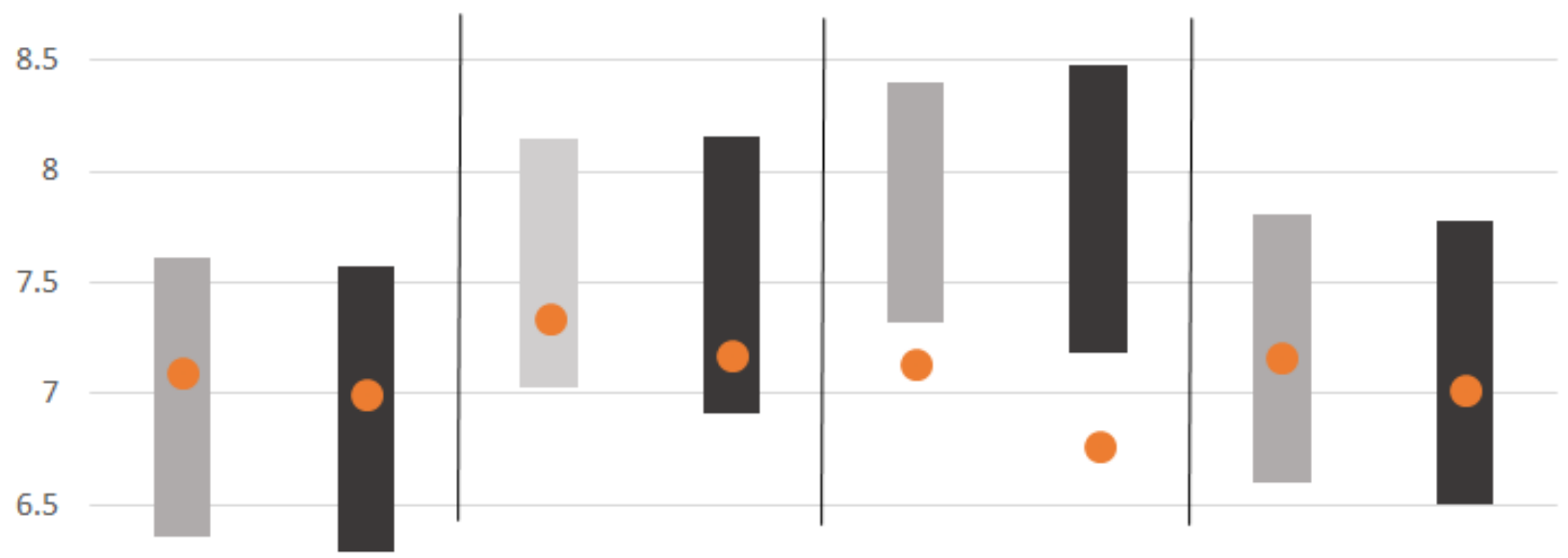

6

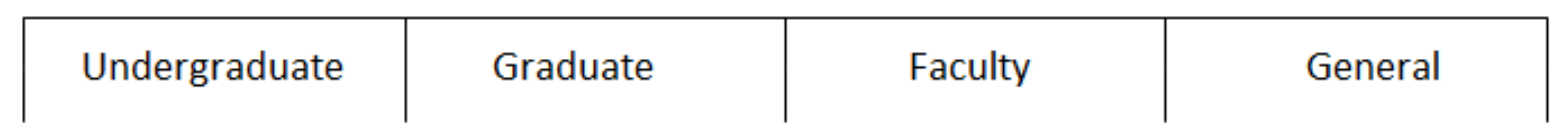

- locate info.: minimum-desired range

navigation: min imum-desired range

perceived mean

The survey results about library usage on the premises and online showed that faculty and graduate students constituted a much higher percentage of frequent (daily and weekly) online users, while undergraduate students tended to use onsite resources more than faculty or graduate students (see Figure 2).

\section{Figure 2: Library Usage - Premises vs Online}

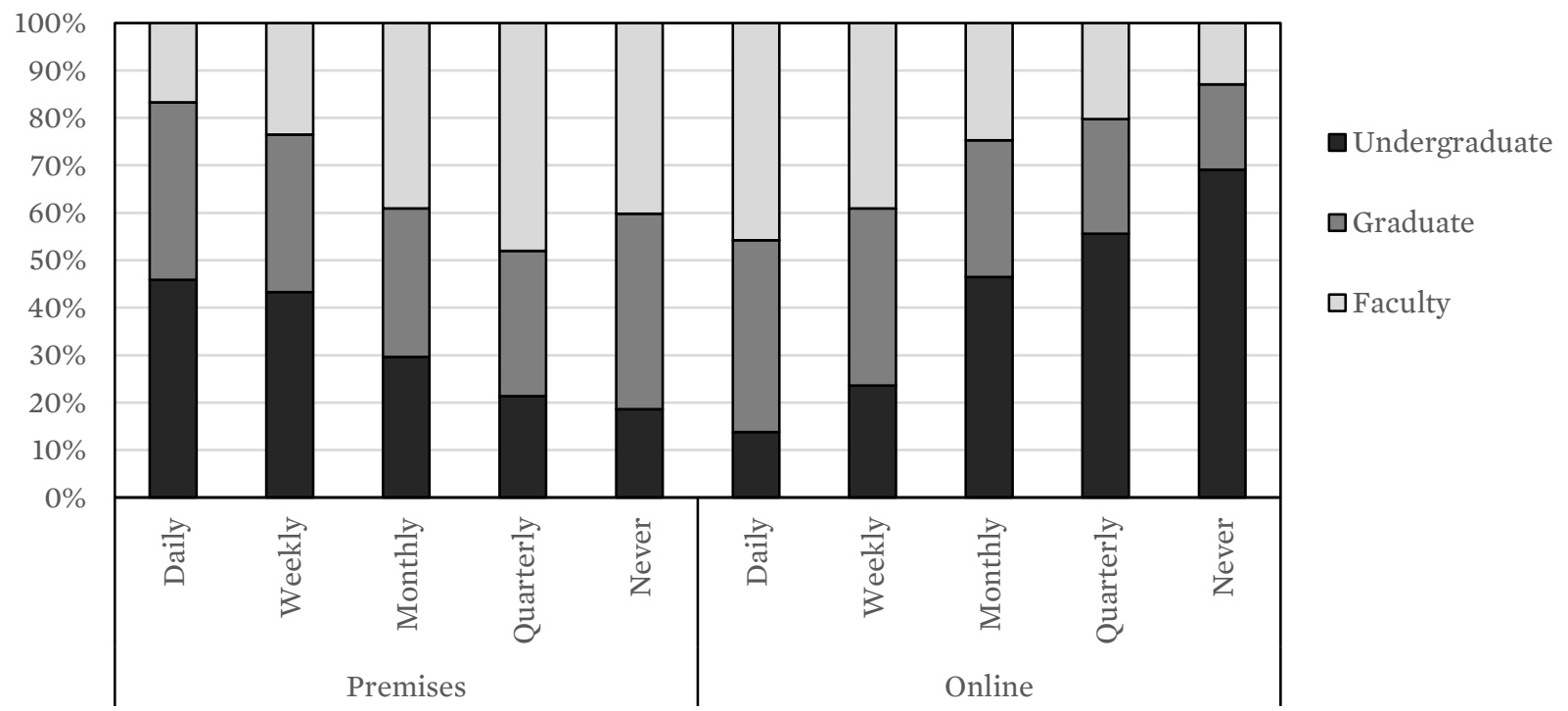

In comparing user satisfaction and usage, faculty and graduate students used the website more and had higher expectations, but they were not satisfied with the offerings in information access and website navigation; undergraduate students used onsite resources much more than online resources, and they were more satisfied with the website. 
Beyond the survey questions, out of the 1,433 participant comments, 17 were coded under the subtopic "Website." Some of the comments referred to more than one aspect of the website. UX team members could not always determine whether ambiguous comments related to the website or discovery tool, because users did not distinguish between them. In this analysis, they tried to exclude comments about the discovery tool or resources such as databases and journals that a person might access through the website.

Table 1: Comments on the Library Website

\begin{tabular}{|c|c|c|c|}
\hline Category & $\begin{array}{l}\text { Number of } \\
\text { comments }\end{array}$ & $\begin{array}{l}\text { User group } \\
\text { distribution }\end{array}$ & Action \\
\hline General & 9 & $\begin{array}{l}\text { Undergraduate- } 4 \\
\text { Graduate-4 } \\
\text { Faculty-1 }\end{array}$ & \\
\hline Navigation & 5 & $\begin{array}{l}\text { Undergraduate-1 } \\
\text { Graduate-3 } \\
\text { Faculty-1 }\end{array}$ & $\begin{array}{l}\text { Add a guide to explain the } \\
\text { homepage content and online } \\
\text { services }\end{array}$ \\
\hline Physical resources & 1 & Undergraduate-1 & \\
\hline $\begin{array}{l}\text { Other research tools: Google } \\
\text { Scholar, Nvivo, etc. }\end{array}$ & 2 & Graduate-2 & $\begin{array}{l}\text { Add link to Google Scholar and } \\
\text { configuration }\end{array}$ \\
\hline Blackboard \& eRaider & 1 & Undergraduate-1 & Ignore \\
\hline Information coverage & 1 & Graduate-1 & \\
\hline Currency & 1 & Graduate-1 & \\
\hline Major-based information & 1 & Graduate-1 & $\begin{array}{l}\text { Categorize personal librarians by } \\
\text { college and area }\end{array}$ \\
\hline Recording studio & 1 & Undergraduate-1 & Contact the recording studio \\
\hline
\end{tabular}

These were the directly actionable suggestions in the comments:

- Five out of seventeen commenters experienced difficulties navigating the website. One suggested giving a training about the website. A reference librarian added a new LibGuide to instruct users on the features of the website.

- Despite the fact that only one participant suggested including Google Scholar as a research tool, some personal librarians taught students how to use Google Scholar and set up TTU Libraries as "My Library" on Scholar. Because the librarians were in favor, the web librarian decided to add Google Scholar to the quick links section on the homepage.

- One graduate student recommended offering major- or discipline-based information. Considering that personal librarians support teaching, learning, and research by subject area, the list of librarians was reorganized by college and subject.

- One comment suggested adding links to university resources like Blackboard or eRaider. We decided to ignore the request because the library was not responsible for these services and users can easily find these links through searching or on other TTU sites.

The comments were only useful up to a point in resolving issues. The authors needed to conduct further research to gain a better understanding of the problems identified in the two survey questions. Farrell introduced over 60 UX research methods and activities by stage in the design cycle and gave clues on which to use when. ${ }^{7}$ Rohrer analyzed 20 user research methods along dimensions of attitudinal or behavioral, qualitative or quantitative, context of use, and development phase. ${ }^{8}$ Both Farrell and Rohrer agreed that it is not realistic or necessary to use all the methods in a given project, but it is often helpful to use a mix of methods to obtain combined insights and ensure validity. The authors used several methods to test and evaluate the libraries' website homepage and navigation to further understand the existing problems and users' expectations: $\mathrm{X} / \mathrm{O}$ tests to allocate valuable home page real estate to the services and features of most interest to users; card sorting to design a more understandable website navigation; usability testing to evaluate whether common tasks could be performed easily; heuristic evaluations of frequently used 
webpages to see if they conformed to accepted usability principles; A/B tests to compare different design prototypes; and subsequent surveys to re-evaluate the modifications.

\section{$\mathrm{X} / \mathrm{O}$ Tests}

An X/O test is a quick survey, where participants circle items they use or like on a website and cross out items they do not. ${ }^{9}$ The web librarian and UX department conducted X/O tests of the library homepage in the fall 2016 semester though the spring 2017 semester. They divided the homepage into 15 areas, and 187 participants finished the X/O tests. The three most-used areas were the search box, menu, and library hours. Some users circled specific services or resources they had used before. The top three were study space reservations, EBSCO (database), and Turnitin (a plagiarism-checking tool).

Figure 3: Use of All Areas on the Library Homepage

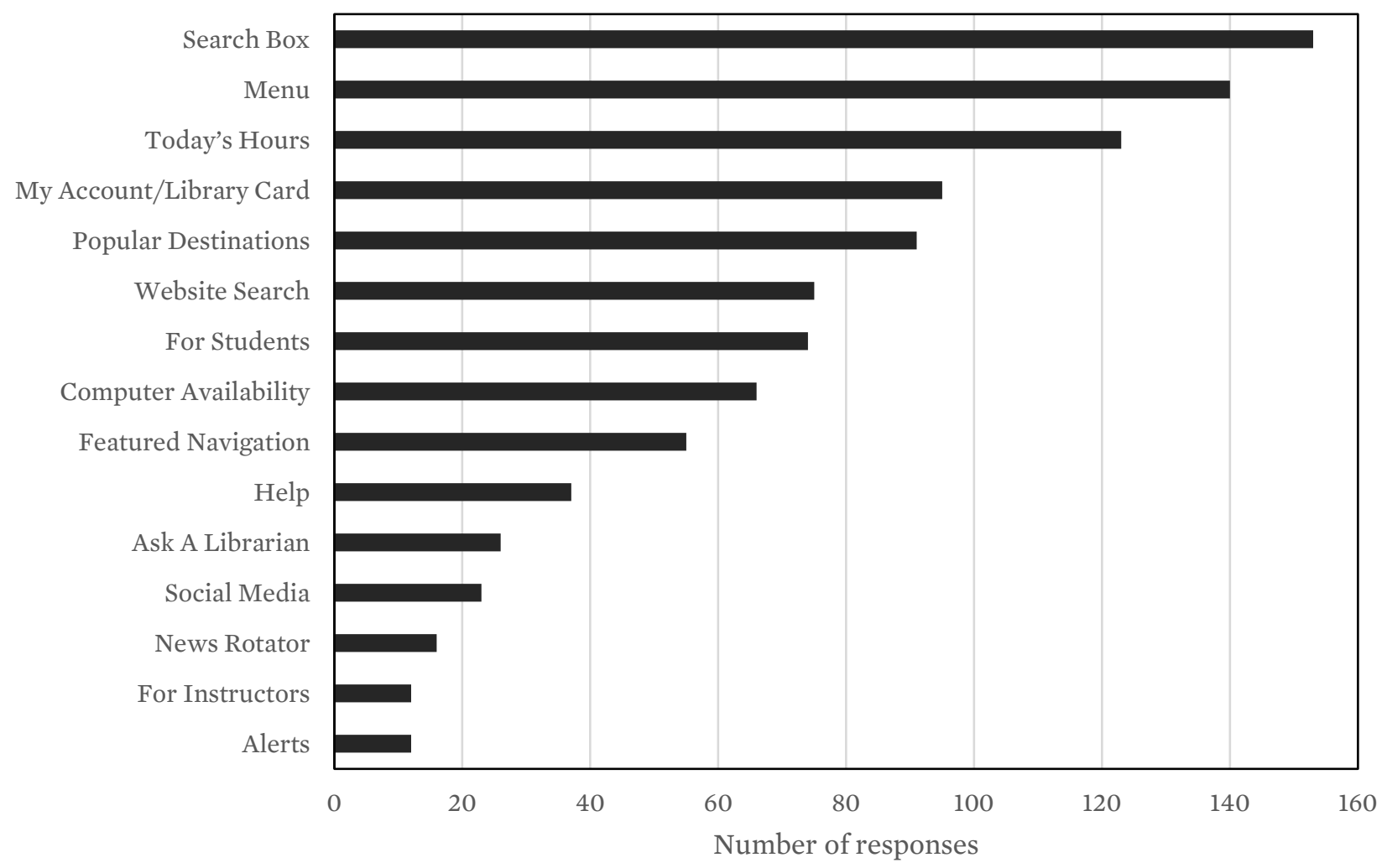

The web librarian reviewed the usage statistics from Google Analytics in conjunction with the X/O test results and adjusted the homepage:

- A section was created to host the most-used services and resources-Document Delivery, study space reservations, "my library account," personal librarians, citation style guides, and printing.

- The areas "For students" and "For instructors" were replaced with the section "Information for..." which displayed information to targeted groups.

These were lessons learned about the X/O method:

- Most X/O tests were conducted inside the university library, a space more frequented by undergraduates, so 149 out of 187 participants were undergrads. The authors would sample graduate students and faculty to make results more representative, because those groups use the website more frequently than undergraduates. 
- Even though the alerts section was least-used, it remained because it was the channel where the libraries delivered system updates to users.

- The X/O tests included pre-survey questions to collect participants' demographic information and services they used on the website. Some users circled several areas but reported that they barely used the library website; others checked multiple services but circled only one or two areas in the $\mathrm{X} / \mathrm{O}$ tests. These contradictions are a caution with self-reported responses. In deciding which items to keep on the homepage, the web librarian referred to both X/O test results and Google Analytics to mitigate the bias from self-reported data.

\section{Card Sorting}

LibQUAL results showed that users experienced difficulties navigating the libraries' website. The web librarian decided to use card sorting, which is a method to help design or evaluate a website's information architecture, to redesign the menu structure. Card sorting has two basic types, open and closed. Typically, in open card sorting sessions, participants are asked to organize cards into groups which make sense to them and label these groups. Closed card sorting uses predefined categories. ${ }^{10}$

The libraries' website had a four-level navigation system with 88 items, which was mainly structured around library departments. The web librarian picked 53 terms, printed these terms and their descriptions onto the two sides of colored card stock, and conducted four rounds of pilot tests among library staff and student assistants. After the pilot tests, terms related to collections or specific user groups were removed, reducing the number of cards to 27 . The web librarian clarified card descriptions and simplified test procedures and instructions to minimize confusion.

The subsequent official open card sorting exercises with students went smoothly, and results were implemented as follows:

- The department-based menu structure was replaced with service-based and user group-based navigation.

- The four-level menu system was changed to three levels.

- Some sub-menu items were positioned in several places to increase their visibility and meet different perspectives. For example, Document Delivery (interlibrary loan) was under menus for both "Search \& Check Out" and "Research \& Teaching Support."

Table 2: Menu Item-Level Changes

\begin{tabular}{|l|l|l|}
\hline Navigation Level & Old Site & New Site \\
\hline Level 1 & 7 & 5 \\
\hline Level 2 & 18 & 21 \\
\hline Level 3 & 42 & 113 (14 duplications) \\
\hline Level 4 & 21 & - \\
\hline
\end{tabular}

These were lessons learned about the card sorting method:

- Pilot tests were helpful in determining the labels and descriptions used on the cards and optimizing procedures.

- In the pilot tests, library staff and student assistants developed meaningful category labels. In the official tests, students used vague terms such as "resources," "services," or even "helpful stuff," and did not come to a consensus about the categories. It was difficult to see a clear pattern because students suggested too many categories. The new navigation system was a combination of the 
categories produced during the pilot tests and the official tests. If the official tests were changed to closed card sorting using labels developed in pilot tests, the results could be more controlled and useful.

- A bonus of pilot tests with library staff was obtaining buy-in among colleagues. Several librarians said they did not expect such difficulties organizing web content into categories that would make sense to students as well as to themselves.

\section{Unmoderated Usability Testing}

The UX department recruited students to participate in unmoderated usability tests to observe whether students could easily complete common tasks on the library website. Usability tests would provide behavioral, instead of self-reported, attitudinal data. Participants were asked to complete four simple tasks and then complete a short questionnaire composed of open-ended questions about their overall experience using the website and the System Usability Scale (SUS). Twenty-eight students participated in the tests.

No changes were made to the website as a direct result of the unmoderated usability testing, because testers were generally able to complete the tasks successfully. However, participant comments suggested ideas for future studies, such as evaluating the study space reservation system. These were lessons learned about the unmoderated usability testing method:

- Unmoderated usability tests did not require as much staff involvement during the testing, so many tests could be conducted in only a couple of hours.

- It is critical to run multiple pilot tests before testing. If testers do not understand the instructions or there are other problems with the testing design, you may not know it until after tests are completed. In this case, a few testers tried to answer some questions in the task scenarios without using the website.

- Many post-survey comments were very general, i.e., "It's good" or "It's great." There was not much actionable feedback. When watching the recordings of the tests, the UX department felt frustrated that they could not follow up on unexpected behaviors. These issues are less problematic in moderated testing when a facilitator can ask probing questions.

\section{Heuristic Evaluations}

The UX librarian collaborated with the TTU faculty member instructing the undergraduate usability testing course to create an assignment for practicing heuristic evaluations. The heuristic evaluation is a quick and comparatively inexpensive way to evaluate a website/page and compare it against accepted usability principles. The professor instructed students to evaluate the libraries' redesigned site using "Jakob Nielsen's 10 Usability Heuristics for User Interface Design." ${ }^{11}$ Students were randomly assigned to review one of three frequently used webpages: the home page, the employment application page, or the library account page. The professor shared evaluations from 13 students in which they identified major problems, minor problems, cosmetic or low priority problems, and made recommendations for improvement. The web librarian and UX department aggregated the findings in a spreadsheet to assist with further exploration and resolution of issues.

Some issues evaluators mentioned in their reports were built in to the university-level website template, and these could not be resolved. The web librarian made the following changes to the home page:

- An indicator was added showing how many slides were in the news rotator.

- An "Advanced Search" button beside the discovery search box that caused users to commit errorsthey thought the button would submit their query-was removed.

- Titles were added to quick link lists, such as "Find Articles."

These were lessons learned about the heuristic evaluation method:

- It does not require a high level of expertise to conduct a heuristic evaluation. 
- Having multiple evaluators review the websites helped find patterns and areas that were repeatedly identified as problematic.

- The partnership with a class instructor and students presented many benefits-the libraries received detailed feedback from students, and students had an opportunity to do relevant "fieldwork" that supported their curriculum. A drawback from receiving written reports via the professor and not communicating directly with the students was that there was not a process to follow up with them. The problems they listed could not always be replicated with only the information they provided.

\section{A/B Tests}

After the new website was launched, at a monthly faculty meeting, librarians gave feedback on the new site, especially the homepage. At the center of the homepage, there was an area containing six colorful squares linked to six most-used services. It became the center of controversy: some librarians believed these colors made the services more visible while others thought they were not academic and looked childish. In the meeting, the squares were given a nickname: Post-it.

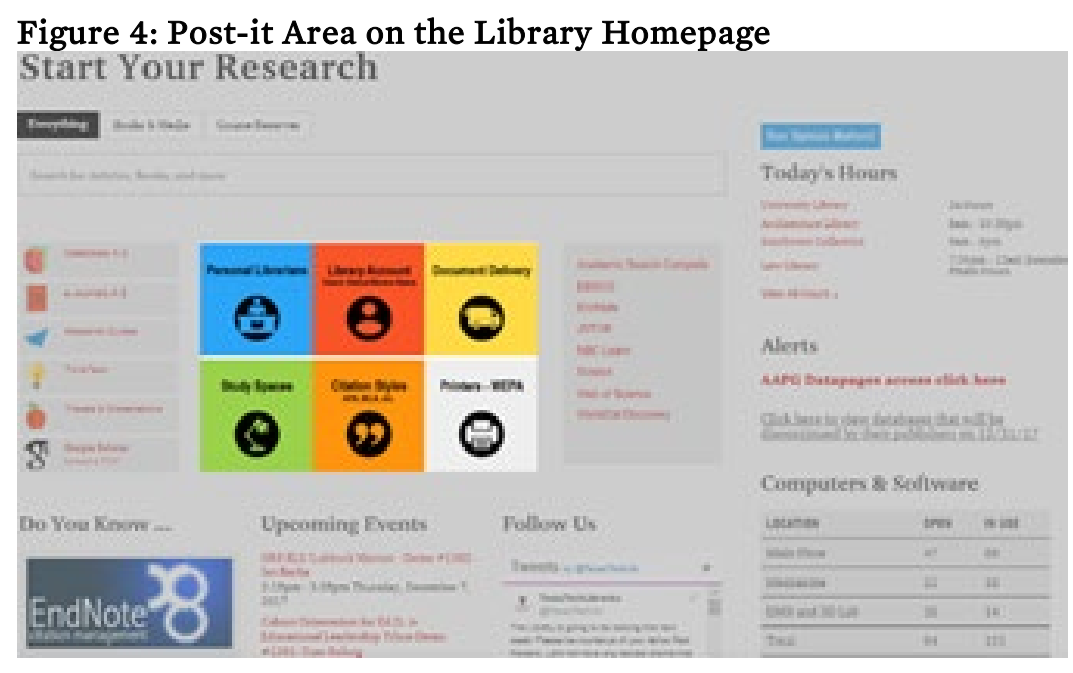

To learn students' opinions on this Post-it area, the UX department and the web librarian conducted further study with A/B testing. The web librarian created two additional designs that addressed comments from the librarians for comparison to the original design. Version A was the original design. Version B was a simplified version using the university's black and red color scheme and single-line titles. Version C was a combination of Version A and B color-wise; subtitles were added to each square and the icons were enlarged. 


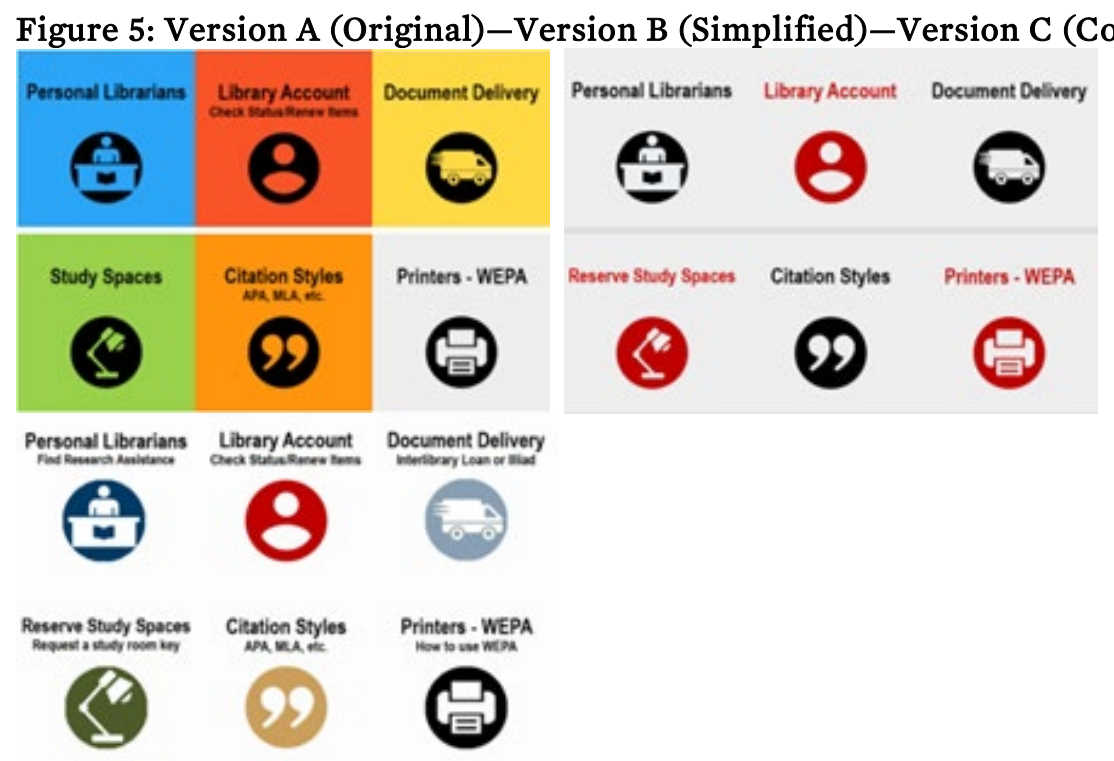

The UX department and web librarian ran tests simultaneously. Each participant was randomly assigned to use a different version of the site to complete set tasks. Afterward, they viewed all three designs and stated their preference and offered comments on colors, language, and icons. The UX department reported the results and made recommendations:

1. Continue to use the design with bright colors that makes the services stand out on the homepage.

2. Make the clickable area clearer by adding a border or white space around squares.

3. Incorporate subtitle text to explain the following services: personal librarians, library account, Document Delivery, and citation styles, which are not universally understood.

4. Explore whether a different icon for study spaces would be more meaningful.

Figure 6: User Preferences on 3 Designs

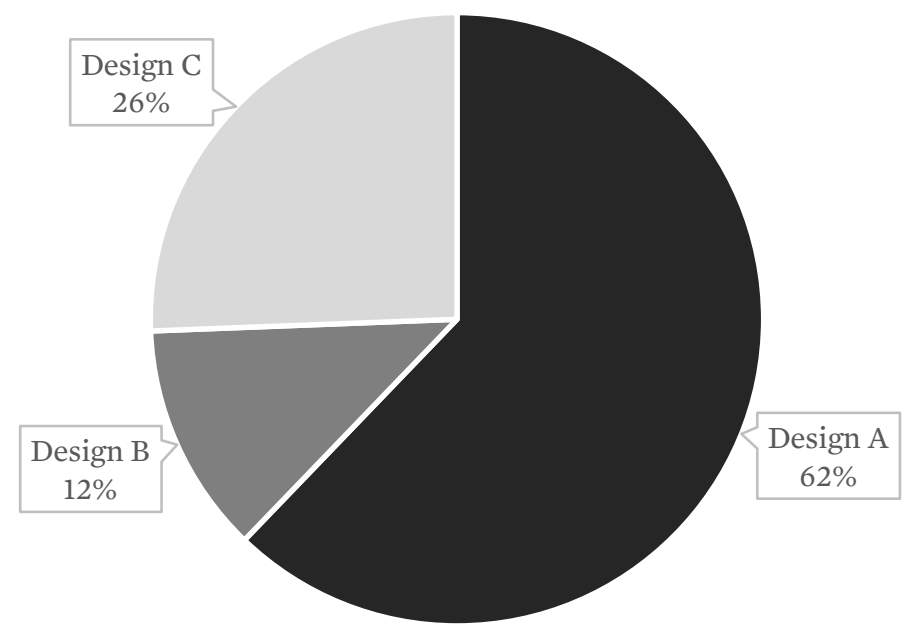


The web librarian implemented these suggestions. The new Post-it area looks like Figure 7.

Figure 7: New Design after Implementing Suggestions
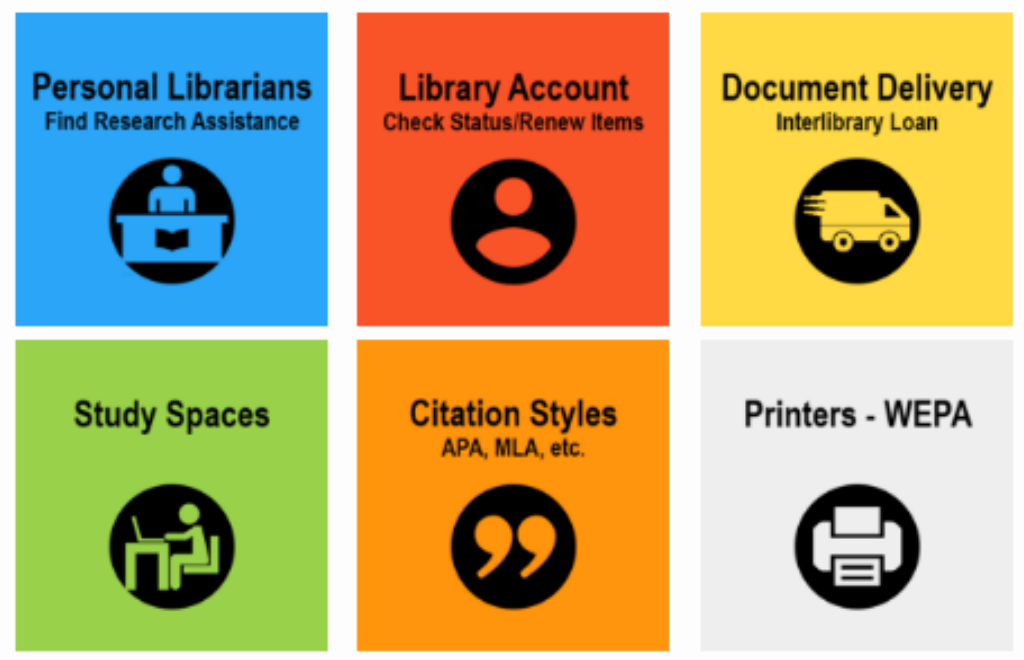

These were lessons learned about the A/B test method:

- At the start, the UX department and web librarian were doing a usability test in which they planned to compare the time required to complete tasks on each version as well as participants' preferences.

- After conducting nine usability tests, they switched to a survey and simply asked participants to choose their preferred design.

- Libraries probably cannot perform an A/B test the way a corporate website can. An authentic A/B test would randomly show different versions of the website to different visitors. "A/B testing can only be used for projects that have one clear, all-important goal, that's to say a single KPI (key performance indicator)" that is measurable, such as sales, new email newsletter subscriptions, downloads of a paper, etc. ${ }^{12}$ Libraries are hesitant to create control and test groups where one group might receive less-preferable designs. Library websites, especially home pages, may not have outcomes that can be widely, usefully measured. Employees may not have the technical expertise or system capability to display different designs at random.

\section{Subsequent Survey}

In the months following LibQUAL, the web librarian and UX department had conducted several tests and made many changes to the website. The UX librarian planned to reassess those changes during the annual all-student survey administered by the campus, which reached about 6,000 students. In contrast to LibQUAL, where the libraries had little control over the questions asked, the all-student survey could be more tailored and specific about areas classified as problematic, such as the website. Students were asked to agree or disagree with the following statements: the information I need is easy to locate, the site allows me to complete the tasks I need to, and the overall design is appealing. The percentage of respondents who agreed with each statement ranged from $81-84 \%$. 
Figure 8: All-student Survey Results

\section{Rate your experience with the redesigned website (library.ttu.edu) this semester}

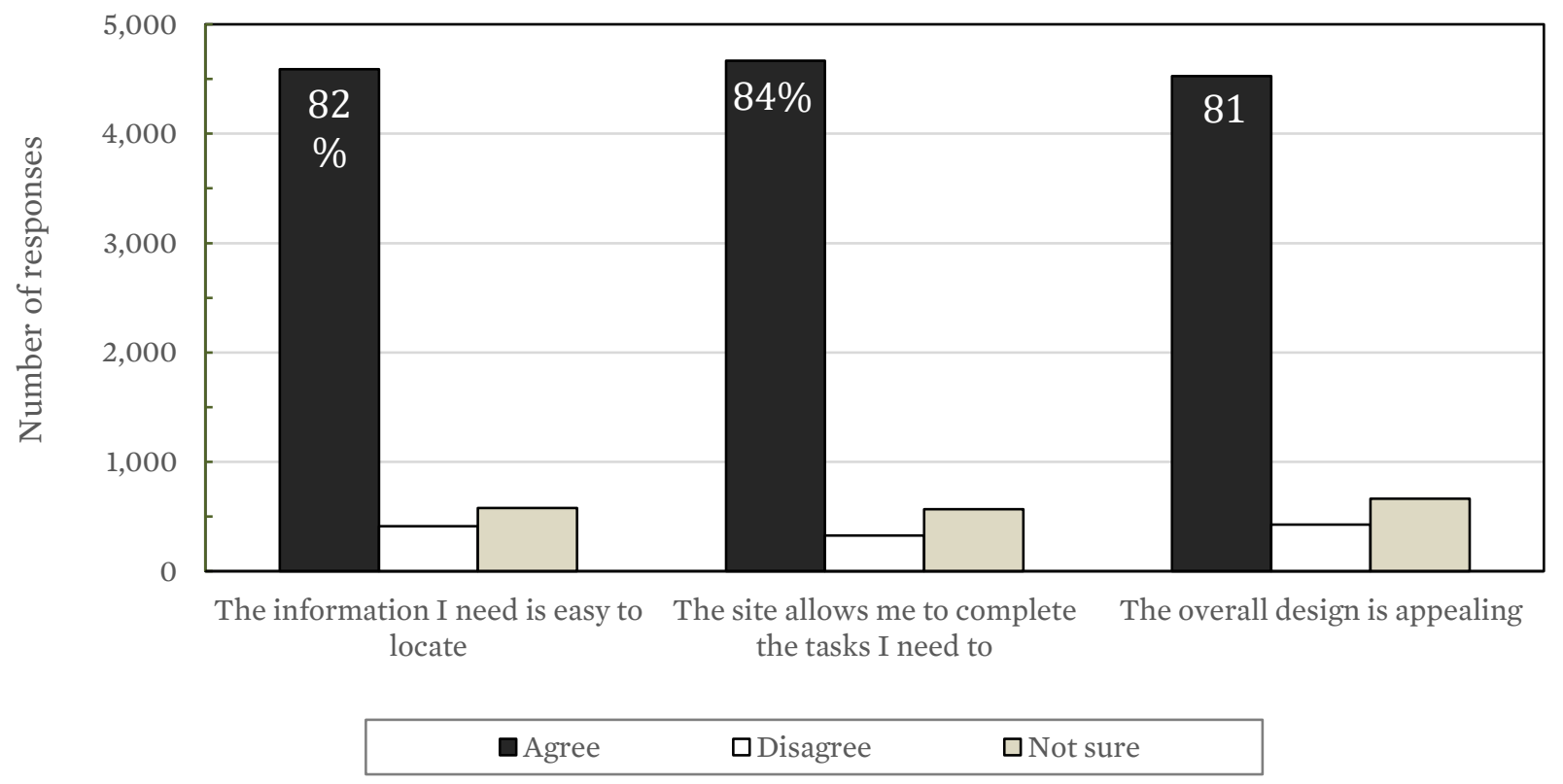

These were lessons learned from conducting this survey:

- A relatively high number of respondents answered "Not sure." It is unknown if this is because those respondents did not use the library website or if it was due to another factor.

- This was a student survey that did not include responses from faculty, who were less satisfied with the website than students. The UX department will seek other ways to reach faculty for their input.

- Like LibQUAL, this survey asked general questions that provided data about users' overall impressions rather than about specific issues. With such broad questions, no ability to screen participants, and no follow-up mechanism, you should not expect to get enough information to resolve individual issues.

\section{Conclusion}

The LibQUAL survey results provided a foundation that generated research questions related to specific areas. The UX department started by making the data more understandable to stakeholders and involving them in the process of reviewing and analyzing the data. Then they collaborated to investigate the problems and potential issues and implement changes.

The authors described how to iteratively test the UX of a website homepage and navigation system using several complementary methods. They adapted their methods during testing in order to gather more feedback. In the process, they learned about the strengths and drawbacks of the methods and obtained experience using each one. Each method helped evaluate different aspects of the library website. This shows ways to research a problem from multiple angles to triangulate several data sources.

These strategies extended the value of survey results and made assessments more effective and practical. The authors moved the library "from data to action" by involving stakeholders and collaborating on further studies, making changes, and then reassessing. Through this, they obtained answers to some of the questions raised by LibQUAL. This pattern can be used not only for a website but for evaluating other services and spaces. 
-Copyright 2019 Kimberly K. Vardeman and Jingjing Wu

Notes

1. Esther Carrigan, "Libraries Act on Their LibQUAL+ Findings: From Data to Action," Journal of the Medical Library Association 93, no. 4 (2005): 504.

2. Selena Killick, "Analysis and Interpretation of the LibQUAL $+{ }^{\circledR}$ Results" (Presentation, SciencesPo, Paris, France, June 26, 2012), https://www.libqual.org/\%5Cdocuments\%5CLibQual\%5Cpublications\%5CKillick_2012_Paris_Results .pdf.

3. Raynna Bowlby, "It's Not about You! Using LibQUAL ${ }^{\circledR}{ }^{\circledR}$ at Brown University and at the University of Connecticut Libraries" (Presentation, American Library Association Midwinter Meeting, San Diego, CA, January 10, 2011),

https://www.libqual.org/documents/LibQual/publications/2011_ALA_SanDiego_Bowlby.pdf.

4. Brown University LibQUAL $+{ }^{\circledR}$ User Assessment Group, "Methodology for Coding Qualitative Data (User Comments)," 2005, accessed January 15, 2019, http://www.libqual.org/documents/admin/BrownU_2005_LQ_qual_method.pdf.

5. Christina Nilsen, Re: taxonomy for coding of LibQUAL + comments, LibQUAL ${ }^{\circledR}$ project participant discussion list, April 7, 2017.

6. Michael M. Rawls, Re: taxonomy for coding of LibQUAL+ comments, LibQUAL $+{ }^{\circledR}$ project participant discussion list, April 5, 2017.

7. Susan Farrell, "UX Research Cheat Sheet," Nielsen Norman Group, last modified February 12, 2017, https://www.nngroup.com/articles/ux-research-cheat-sheet/.

8. Christian Rohrer, "When to Use Which User-Experience Research Methods," Nielsen Norman Group, last modified October 12, 2014, https://www.nngroup.com/articles/which-ux-research-methods/.

9. SuHui Ho, "What do Users Want from Our Website? A User Study of the UC San Diego Library Website" (Presentation, Designing for Digital Conference, Austin, TX, April 6-7, 2016), https://www.slideshare.net/shh2/what-do-users-want-from-our-website.

10. “Card sorting," U.S. Department of Health \& Human Services, accessed January 15, 2019, https://www.usability.gov/how-to-and-tools/methods/card-sorting.html.

11. Jakob Nielsen, "10 Usability Heuristics for User Interface Design," Nielsen Norman Group, last modified, January 1, 1995, https://www.nngroup.com/articles/ten-usability-heuristics/.

12. Jakob Nielsen, "Putting A/B Testing in Its Place," Nielsen Norman Group, last modified August 15, 2005, https://www.nngroup.com/articles/putting-ab-testing-in-its-place/. 